\title{
Transtheoretical model key constructs applied to the intervention \& treatment of weight cycling \& yoyo dieting cognitive-affective bases of health for weight management
}

Volume 3 Issue 3 - 2016

\section{TTM weight cycling therapy \\ Objective}

The purpose of this presentation is to introduce a Behavioral Health Consultant (BHC) prescribed and monitored program utilizing the Transtheoretical Model (TTM) stages of change for the management of weight cycling as a standalone treatment or in conjunction with medical treatment.

\section{Introduction}

Weight cycling is a complex and chronic condition that involves the repeated loss and regain of body weight. ${ }^{1,2}$ Discussions should be opened up on how the Transtheoretical Model (TTM) can be utilized and strengthened as a treatment for weight cycling in certain populations. The well-established TTM model is utilized successfully by behavioral healthcare practitioners and fitness and wellness experts to assist populations presenting the need of weight loss and weight loss maintenance. "Improving our understanding of the differences and the dynamics of the shift between action and maintenance has the potential to support sustainable weight maintenance". ${ }^{4}$

\section{Weight cycling}

a. Weight cycling is a complex and chronic condition that involves the repeated loss and regain of body weight.

b. The condition can include increased physical activity (PA) alone, the combination of PA and dieting, or it can be the result of dieting alone.

c. When weight cycling is a diet regime intended for weight loss it is often referred to as "yo-yo" dieting or the "yo-yo" effect. Moreover, their definitions differ slightly; the terms weight cycling and yo-yo dieting are used interchangeably for the purposes of this article.

d. Weight cycling and yo-yo dieting are not limited to the obese or overweight; $50 \%$ of the population with normal weight yo-yo diet. $^{2}$

e. Demographic groups with normal body weight who perceive themselves as 'fat' due to a multitude of societal pressures weight cycle.

f. Many view a slim-trim aesthetically appealing body image as advantageous for numerous personal and various professional reasons. ${ }^{1,2}$

\section{TTM weight cycling therapist}

My goal as a Behavioral Health Consultant is to keep my weight cycling and yo-yo dieting patients in the TTM maintenance stage as

\author{
Robelyn Garcia,' Daniela Benavidez ${ }^{2}$ \\ 'Arizona State University, USA \\ ${ }^{2}$ United States Sports Academy, USA
}

\begin{abstract}
Correspondence: Robelyn Garcia, Arizona State University, Scottsdale, AZ 85260, USA, Tel 6028459802.
\end{abstract} Email DrRGarcia@asu.edu

Received: January 28, 2016 | Published: February 22, 2016

a continuation of behavioral change therefore becoming their normal lifestyle by adopting a positive and sustainable change (Figure 2).

\section{TTM weight cycling patient}

\section{Patient selection}

Patients are referred to the BHC by the PCP. Although patients often have multiple concerns, the patient's presenting concern relevant to the key constructs of the Transtheoretical Model (TTM) is ongoing weight cycling. This patient presents as a yo-yo dieter and has progressed through the many components and stages of the TTM therefore requiring ongoing weight management and behavioral health counseling and treatment. While treating this patient, her readiness to change her weight has fallen into all of the original five stages of the TTM; 1) Precontemplative, 2) Contemplative, 3) Preparation, 4) Action, and finally 5) Maintenance. ${ }^{3}$ The patient's current stage falls within the action stage with an exit and almost immediate re-entry at the preparation stage. This particular patient's weight loss and weight gain is directly and concisely related and correlated to the key components of the TTM as reflected by the number (lbs) on the scale each and every morning when she weighs herself.

\section{Transtheoretical model (Figure I \& Table I)}

i. The original five stages of the TTM are:
a. Precontemplative
b. Contemplative
c. Preparation
d. Action
e. Maintenance 
ii. The additional Relapse stage occurs in weight cycling creating a continuous cycle.

iii. The Maintenance stage for weight cyclers needs to involve a shift from weight loss to weight management. This will create a continuation of a sustainable and habitual behavioral change. ${ }^{3,4}$

iv. Figure $1 \&$ Table 1 illustrate the TTM adapted for Weight Cycling Treatment.

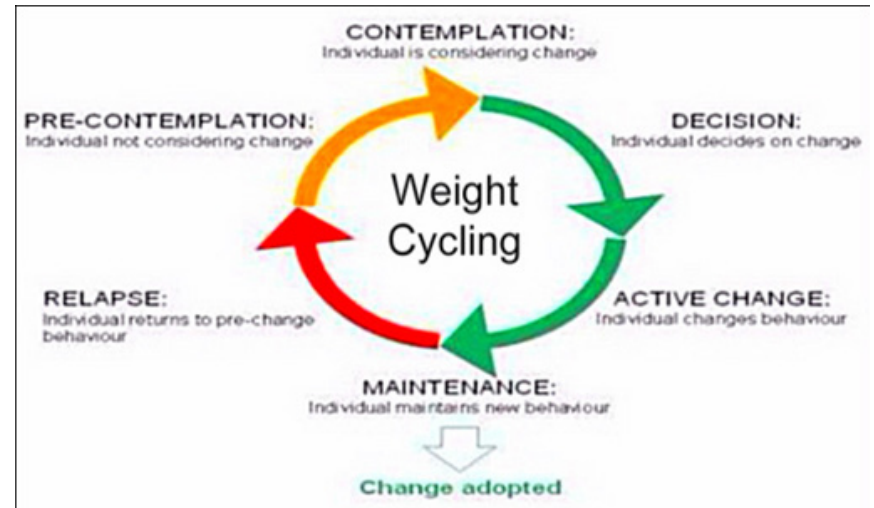

Figure I Transtheoretical Model. ${ }^{5,9}$

Table I Transtheoretical (TTM) Stages, Behavioral Features \& Interventions for Weight Cycling ${ }^{5,6}$

\begin{tabular}{|c|c|c|}
\hline Stage of Change & Behavioral Features & Interventions \\
\hline Precontemplation & $\begin{array}{l}\text { Unaware of the need to } \\
\text { change }\end{array}$ & $\begin{array}{l}\text { Review the effects of } \\
\text { obesity on physical and } \\
\text { mental health and the } \\
\text { potential for developing } \\
\text { comorbidities. }\end{array}$ \\
\hline Contemplation & $\begin{array}{l}\text { Considering change using } \\
\text { available information }\end{array}$ & $\begin{array}{l}\text { Improve awareness } \\
\text { of factors that lead to } \\
\text { weight gain; explore } \\
\text { personal goals that } \\
\text { could be achieved } \\
\text { through weight loss, } \\
\text { available behavioural } \\
\text { options, and decisional } \\
\text { balance. }\end{array}$ \\
\hline Planning & $\begin{array}{l}\text { Developing a strategy for } \\
\text { change }\end{array}$ & $\begin{array}{l}\text { Identify specific } \\
\text { behaviours that } \\
\text { will be needed for } \\
\text { improving weight } \\
\text { including monitoring, } \\
\text { cognitive restructuring, } \\
\text { medication adherence. }\end{array}$ \\
\hline Action & $\begin{array}{l}\text { Engaging in active } \\
\text { behaviours to change }\end{array}$ & $\begin{array}{l}\text { Employee appropriate } \\
\text { dietary, physical activity, } \\
\text { medication management, } \\
\text { stress management, } \\
\text { social support, and } \\
\text { environmental control } \\
\text { strategies focused on } \\
\text { achieving lifestyle goals. }\end{array}$ \\
\hline Maintenance & $\begin{array}{l}\text { Sustaining change that } \\
\text { was made }\end{array}$ & $\begin{array}{l}\text { Establish and utilize } \\
\text { relapse prevention } \\
\text { and contingency } \\
\text { planning strategies to } \\
\text { consistently engage } \\
\text { in behaviours that } \\
\text { focuses life style goals } \\
\text { as motivators for } \\
\text { effectively regulates } \\
\text { weight. }\end{array}$ \\
\hline
\end{tabular}

\section{Behavioral counseling strategies}

\section{Patient interventions to improve health outcomes}

a. Participate in Nutrition \& Exercise Counseling: Develop a Specific Program 5,6

b. Plan What You would be Doing Different When You Make the Change ${ }^{7,8}$

c. Replace Unhealthy Foods with Healthy Foods

d. Replace Unhealthy Activities with Healthy Activities

e. Be Specific When Setting Goals \& Document Progress Daily

f. Join a Support Group

g. Research Educational Resources Online (See Appendix)

\section{Measurement of progress toward health outcomes}

a. Patient Begins to Self-Manage with Less Thought of lbs on the Scale

b. Patient's Focus Moves from Weight To Life's Activities

c. Time Spent in the Maintenance State is the Most Significant Measurement ${ }^{8-10}$

\section{Discussion}

Although there is some crossover and integration between TTM action and maintenance more research is needed to explore, identify and explain the different processes and motivations between weight loss and weight management once the individual shifts into the TTM maintenance stage. "Applied to weight management, weight loss occurs during the action stage and weight-loss maintenance occurs during the maintenance stage". ${ }^{4}$ For many weight loss patients the maintenance stage resembles a cyclic exit and entry to behavioral health change. This can be viewed as TTM cycling or, more specifically for these patients, weight cycling. The patient that presents as a weight cycler repeatedly progresses through the stages of the TTM therefore requiring ongoing weight management and behavioral health counseling and treatment. ${ }^{5,11}$ When utilizing the Transtheoretical Model for weight loss and weight loss maintenance therapists and patients need to focus on a continuation of behavioral change, not a termination of behavioral change.

\section{Conclusion}

Assessing this patient's current stage and readiness to lose weight and to change weight-related behaviors is imperative in helping the patient's attempts to break the cycle of yo-yo dieting, maintain a successful weight loss program, and improve overall health. It is important to note that this patient is not obese or even overweight as assessed by Body Mass Index (BMI) measurement of weight (lb)/ height (inches) $2 X 703.5,10$ Obesity is categorized by a BMI of 30 and above, overweight is 25-29.9, and normal weight falls within 18.524.9. . $10^{10}$ This patient is in the normal weight category and weight cycles between 18.5 and $22 \mathrm{BMI}$ while losing and regaining 5 to 25 lbs through the TTM stages per weight cycle.

Weight cycling and yo-yo dieting are not limited to the obese or overweight as up to 50 percent of the US population with normal body weight attempt to lose weight at any given time ${ }^{1,8}$. Demographic groups with normal body weight who perceive themselves as fat due to a multitude of societal pressures also attempt weight loss. Many individuals, including this patient, view a slim aesthetically 
appealing image as advantageous for numerous personal and various professional reasons.

It is evident that remaining at a stable weight and on a healthy diet provides the best outcomes for health, however research reveals that weight cycling does not decrease lifespan and is more beneficial to health than being obese or overweight. ${ }^{6,8,11,12}$ Therefore the maintenance stage for this patient needs to be a continuation of behavioral change, not a termination of behavioral change. The overall time spent in the maintenance stage is the most reflective measurement of successful health outcomes for this patient and others that fall within this demographic. Behavioral Health Consultants can apply this understanding to counseling their clients for long-term weight maintenance and weight cycling prevention.

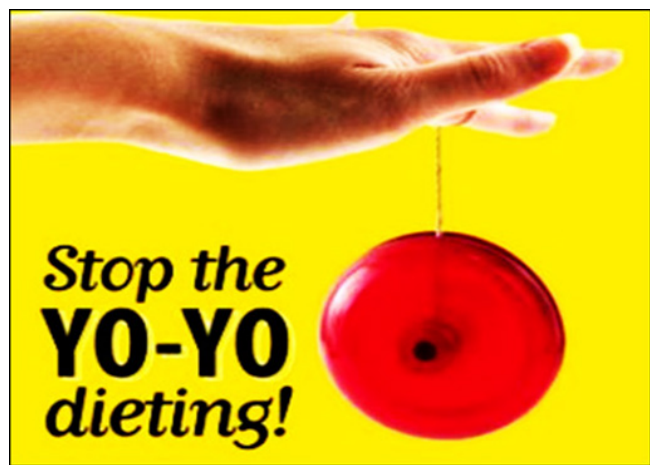

Figure 2 TTM Weight Cycling Therapy.'

\section{Appendix}

1. Onlineresources

Recommended online patient resources to support the health behavior changes for treating weight cycling.

2. How to Stop Yo-Yo Dieting. (http://www.womenshealthmag. com/weight-loss/diet-information)

3. WebMD Weight Cycling Research \& Treatment. (http://www. webmd.com/diet/weight-cycling)

4. LIVESTRONG Advice on Yo-Yo Dieting. (http://www. livestrong.com/article/353915-health-risks-of-yoyo-dieting)

5. Arizona State University Body Image \& Binge Eating. (https:// eoss.asu.edu/wellness/bodyimage)

6. Arizona State University Eating Disorders Self-Care. (https:// eoss.asu.edu/health/selfcare/eatingdisorders)

7. A Reading List for Yo-Yo Dieters. (http://askmaryrd. com/2012/01/29/my-favorite-books-for-emotional-eaters-andyo-yo-dieters)

\section{Acknowledgments}

None.

\section{Conflicts of interest}

None.

\section{Funding}

None.

\section{References}

1. Montani JP, Schutz Y, Dulloo AG. Dieting and weight cycling as risk factors for cardiometabolic diseases: who is really at risk? Obes Rev. $2015 ; 1: 7-18$.

2. Thomas JG, Bond DS. Review of Innovations in Digital Health Technology to Promote Weight Control. Curr Diab Rep. 2014;14(5):485.

3. Armitage CJ. Is there utility in the transtheoretical model? British Journal of Health Psychology. 2009;14(2):195-210.

4. Macchi CR, Russell C, White M. Shifting processes model: a conceptual model for sustainable weight management. Fam Syst Health. 2013;31(4):326-337.

5. Garcia RA. Does online "Working Out Work" as a treatment and prevention for depression in older adults? An analysis of a prescribed and monitored exercise program administered via the Internet for senior adults. Arizona State University, Tempe, USA. 2011.

6. Garcia RA. Integrative Mind-Body Medicine as a Treatment for Psychophysiologic Disorders Utilizing the Seven Keys to Treating Stress Illness. Int J Complement Alt Med. 2015;1(3):00017.

7. Prochaska J. How do people change, and how can we change to help many mono people? In: M Hubble, B Duncan, S Miller (Eds.), The heart \& soul of change. American Psychological Association, Washington, DC, USA. 1999. p.227-255.

8. Tiernan K. Chronic Pain \& Opioids, Wk 6: Behavioral Interventions for Chronic Pain in Primary Care. 2014

9. Macchi CR. Transtheoretical Model, Stages of Change \& SelfDetermination Theory: Week . 2015;4.

10. Cordes C. Correlates of Physical Activity: Week 2. 2014.

11. List EO, Berryman DE, Wright-Piekarski J, et al. The effects of weight cycling on lifespan in male C57BL/6J mice. Int J Obes (Lond). 2013;37(8):1088-1094.

12. West R. Time for a change: Putting the Transtheoretical Model (Stages of Change) to rest. Addiction. 2005;100(8):1036-1039. 